\title{
Characterization of Escherichia coli Strains Obtained from Layer Chickens Affected with Colibacillosis in a Commercial Egg-Producing Farm
}

\author{
Azusa SOMEYA ${ }^{1)}$, Koichi OTSUKI ${ }^{2)}$ and Toshiyuki MURASE ${ }^{1,3) *}$ \\ ${ }^{1)}$ Laboratory of Veterinary Microbiology, Faculty of Agriculture, Tottori University, Tottori 680-8553, ${ }^{2)}$ Faculty of Technology, Kyoto \\ Sangyo University, Kyoto 605-8555 and ${ }^{3)}$ The Avian Zoonosis Research Center, Faculty of Agriculture, Tottori University, Tottori 680 \\ 8553, Japan
}

(Received 19 March 2007/Accepted 5 June 2007)

\begin{abstract}
The present study reports colibacillosis of layer chickens in a commercial egg-producing farm in western Japan. Three flocks of chicken at 18-21 weeks of age were affected during the initiation of egg lay. Postmortem examination revealed pericarditis, perihepatitis, airsacculitis, subcutaneous inguinal lesion, and injured cloaca. Escherichia coli was isolated from the lesions of the affected birds. Twenty-two of $26 \mathrm{E}$. coli isolates $(84.6 \%)$ obtained from 18 birds in the 3 flocks showed pulsed-field gel electrophoresis (PFGE) patterns that were considered to be closely associated to each other and arbitrarily designated as pattern A. All the 22 isolates with the PFGE pattern A harbored the putative virulence genes, astA, iss, iucD, tsh, and $c v a / c v i$. Additional 2 PFGE patterns (B and C) were also found in $E$. coli isolates obtained from the affected flocks and had the putative virulence genes in combinations different from those in the pattern A strains. The results suggested that certain E. coli virulence genes and host factors, such as initiation of egg lay may be associated with occurrence of colibacillosis.
\end{abstract}

KEY WORDS: age, colibacillosis, Escherichia coli, layer.

J. Vet. Med. Sci. 69(10): 1009-1014, 2007

Escherichia coli (E. coli) is considered as a member of the normal microflora of the poultry intestine, but certain strains, such as those designated as avian pathogenic $E$. coli (APEC), spread into various internal organs and cause colibacillosis characterized by systemic fatal disease $[1,8]$. The main route of entry is considered to be the respiratory tract due to inhalation of dust contaminated with feces $[6,13]$. The organisms which colonize the air sac or lung subsequently reach the blood stream, translocate into the internal organs, and cause pericarditis, perihepatitis, peritonitis, salpingitis, and other extra-intestinal problems. Several potential virulence factors, including adhesins, iron acquisition systems, hemolysins, anitibactericidal factors, and toxins, have been implicated in promoting the severe disease situations in avian species $[1,8]$. Their roles in pathogenesis have not yet completely been elucidated [8].

APEC is regarded to be one of the principal causes of economic losses in the poultry industry worldwide $[1,8]$. Losses due to colibacillosis in broilers have traditionally described [16]. The importance in layer flocks has also been recognized and some case reports have been demonstrated that colibacillosis can cause severe losses in layer hens [3$5,7,12,17]$.

We have recently encountered colibacillosis that occurred in three flocks at 18-21 weeks of age as they began egg lay. The objective of the present study is to characterize the disease situation affecting the flocks as well as to differentiate the $E$. coli isolates obtained from these cases using pulsed-field gel electrophoresis (PFGE) and identify the dis-

\footnotetext{
* Correspondence to: Murase, T., Laboratory of Veterinary Microbiology, Faculty of Agriculture, Tottori University, Tottori 680-8553, Japan.

e-mail: murase@muses.tottori-u.ac.jp
}

tribution of virulence-associated genes in those strains.

\section{MATERIALS AND METHODS}

Case Report: In this egg-producing farm, approximately 100-day-old pullets were brought from chick-rearing farms every 2 months. Three strains of commercial hen strains (Hy-Line W36, Hy-Line W98, and Laumann LSL Classic) were reared in turn. All birds were kept in environmentally controlled windowless houses. Each house consisted of 2 rooms that were separated by a wall. A flock comprising approximately 27,000 birds was reared in each of the rooms. Flocks 1 (Hy-Line W36) and 2 (Hy-Line W98) were reared in the same house and flock 3 (Laumann LSL Classic) was kept in an adjacent house $10 \mathrm{~m}$ away. Belts connected between the houses and transported the eggs from the houses to a building, in which grading and packaging of the eggs were carried out.

In November 2005 , a total of 27 birds $(0.1 \%)$ in flock 1 at 20 weeks of age suddenly died compared to the normal mortality of less than 5 birds observed at 17-19 weeks of age (Fig. 1). The mortality rate increased to $0.25 \%$ at 22 weeks of age and gradually decreased there after. In flock 2 , a sudden increase in mortality $(0.61 \%)$ was observed in January 2006 when the birds were 19 weeks of age. This high mortality continued into week 20 and then declined. Similarly, mortality in flock 3 increased to $0.04 \%$ at 18 weeks of age in March 2006, reached to $0.31 \%$ at 21 weeks of age, and decreased after that. E. coli was isolated from liver, heart, air sac, thigh joint, and subctaneous inguinal lesion of the affected birds (see below). All flocks started laying at 1821 weeks of age and the egg production reached a plateau at approximately 23 weeks of age (Fig.1). Living birds in 

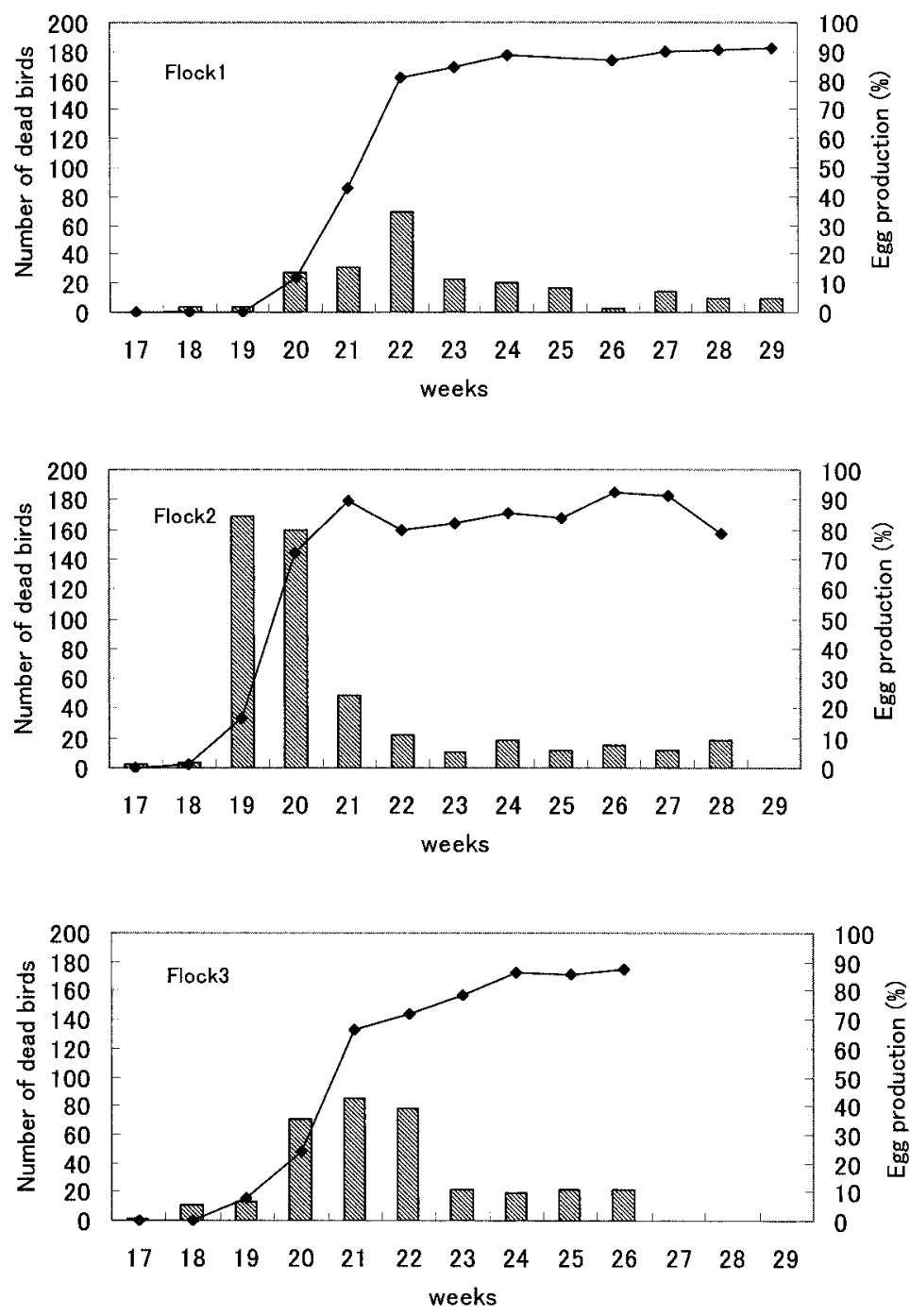

Fig. 1. Changes in the number of the birds found dead (bars) and percentage of the egg production (line graph).

flock 1 , flock 2 , and flock 3 were treated with amoxicillin at 22, 20, and 20 weeks of age, respectively. Amoxicillin was orally administered $(12.5 \mathrm{mg} / \mathrm{kg}$ of body weight $)$ twice a day for 4 days to each chicken. The birds in flock 2 were also treated with sulfamonomethoxine $(20 \mathrm{mg} / \mathrm{kg}$ of body weight, i.m.) for three days at 19 weeks of age because they were partly infected with coccidia.

Postmortem and bacteriological examination: Eight birds in flock 1 at 22 weeks of age, 4 birds in flock 2 at 21 weeks of age, and 6 birds in flock 3 at 20 weeks of age were submitted for postmortem examination. Histopathological examinations were not performed because these birds found dead after postmortem rigidity and were not considered to be appropriate for the examination. Swabs collected from liver, heart, air sac, thigh joint, and subcutaneous inguinal lesion were individually subjected to bacteriological examination by streaking onto Tripto-Soya agar (Nissui Pharma- ceutical Co., Tokyo, Japan) plates supplemented with 5 percent horse erythrocytes and desoxycholate hydrogen sulfide (DHL) agar (Nissui Pharmaceutical Co., Tokyo, Japan). In birds 7 and 8 , liver and heart were simultaneously swabbed (see Table 1) and subjected to bacteriological examination. Because the blood and DHL plates yielded weakly yellowish mucoid colonies and redish colonies, respectively, in pure culture, one colony was picked from each of the plates and the biochemical characteristics were examined using ID test EB-20 (Nissui Pharmaceutical Co., Tokyo, Japan), and identified as E. coli. An isolate from each of the blood agar plates was subjected for further examination. Serotyping of $E$. coli strains were performed by slide agglutination using commercially available $\mathrm{O}$-antisera (Denka Seiken Co., Ltd). Pulsed-field gel electrophoresis (PFGE) patterns of all the isolates obtained were analyzed as described elsewhere [11]. Briefly, the bacterial 
Table 1. Characteristics of E. coli strains obtained from the affected birds

\begin{tabular}{|c|c|c|c|c|c|c|c|c|c|c|c|}
\hline \multirow{2}{*}{$\begin{array}{c}\text { Flock } \\
\text { no. }\end{array}$} & \multirow{2}{*}{$\begin{array}{l}\text { Bird } \\
\text { no. }\end{array}$} & \multirow[t]{2}{*}{ Origin } & \multirow{2}{*}{$\begin{array}{l}\text { PFGE } \\
\text { pattern }\end{array}$} & \multicolumn{8}{|c|}{ Presence of virulence-associated genes ${ }^{\mathrm{a})}$} \\
\hline & & & & ast $A$ & iss & irp2 & papC & іисD & tsh & vat & $c v a / c v i$ \\
\hline \multirow[t]{11}{*}{1} & 1 & Inguen & A1 & + & + & - & + & + & + & - & + \\
\hline & & Thigh joint & A1 & + & + & - & + & + & + & - & + \\
\hline & 2 & Inguen & A1 & + & + & - & + & + & + & - & + \\
\hline & 3 & Inguen & A1 & + & + & - & + & + & + & - & + \\
\hline & 4 & Surface of liver & A1 & + & + & - & + & + & + & - & + \\
\hline & & Parenchyma of liver & A1 & + & + & - & + & + & + & - & + \\
\hline & & Heart & $\mathrm{A} 1$ & + & + & - & + & + & + & - & + \\
\hline & 5 & Air sac & A1 & + & + & - & + & + & + & - & + \\
\hline & 6 & Inguen & A1 & + & + & - & + & + & + & - & + \\
\hline & 7 & Liver and Heart & A2 & + & + & - & + & + & + & - & + \\
\hline & 8 & Liver and Heart & A1 & + & + & - & + & + & + & - & + \\
\hline \multirow[t]{8}{*}{2} & 9 & Inguen & $\mathrm{A} 1$ & + & + & - & + & + & + & - & + \\
\hline & & Liver & A1 & + & + & - & + & + & + & - & + \\
\hline & & Heart & $\mathrm{A} 1$ & + & + & - & + & + & + & - & + \\
\hline & 10 & Liver & B & - & + & + & - & + & - & - & - \\
\hline & & Heart & B & - & + & + & - & + & - & - & - \\
\hline & 11 & Liver & A3 & + & + & - & + & + & + & - & + \\
\hline & & Heart & A3 & + & + & - & + & + & + & - & + \\
\hline & 12 & Liver & B & - & + & + & - & + & - & - & - \\
\hline \multirow[t]{7}{*}{3} & 13 & Liver & A2 & + & + & - & + & + & + & - & + \\
\hline & 14 & Liver & A4 & + & + & - & - & + & + & - & + \\
\hline & & Liver & A4 & + & + & - & - & + & + & - & + \\
\hline & 15 & Inguen & A4 & + & + & - & - & + & + & - & + \\
\hline & 16 & Liver & $\mathrm{C}$ & + & + & + & - & + & + & + & + \\
\hline & 17 & Liver & A2 & + & + & - & + & + & + & - & + \\
\hline & 18 & Liver & A4 & + & + & - & - & + & + & - & + \\
\hline
\end{tabular}

a) + and - , gene detected and undetected, respectively, by PCR.

DNAs prepared in an agar block were digested with 20 units of $X b a \mathrm{I}$, and the DNA fragments were separated by PFGE by using the CHEF-DR II apparatus (Bio-Rad Laboratories, Richmond, CA) in $0.5 \times$ Tris-borate-EDTA buffer with 50 $\mu \mathrm{M}$ thiourea at $14^{\circ} \mathrm{C}$ at $6 \mathrm{~V} / \mathrm{cm}$. The switching times were increased from 0.5 to $50 \mathrm{sec}$ during a total running time of $20.5 \mathrm{hr}$.

Identification of eight putative virulence determinants, $\mathrm{P}$ fimbriae ( $p a p C)$, aerobactin ( $i u c D)$, iron-repressible protein (irp2), temperature-sensitive hemagglutinin ( $t$ sh), vacuolating autotransporter toxin (vat), enteroaggregative toxin (astA), increased serum survival protein (iss), and colicinV plasmid operon genes $(c v a / c v i)$ was performed by PCR using primer pairs and PCR conditions that have been previously reported [5].

\section{RESULTS}

Postmortem examination revealed perihepatitis, pericarditis, and airsacculitis. The affected birds occasionally showed darken inguinal discoloration, and edema and hemorrhage in cloaca (Fig. 2).

All the isolates obtained from the lesions were serologically untypeable. XbaI-digested PFGE patterns obtained were classified by more than 7-band differences between each of two isolates and were arbitrarily designed as pattern $\mathrm{A}, \mathrm{B}$, and $\mathrm{C}$. Isolates belonging to the pattern $\mathrm{A}$ were further distinguished by one- to three-band differences and desig- nated as A1 through A4 (Fig. 3). Of 11 isolates obtained from flock 1, 10 isolates showed an identical pattern (A1). One isolate showing pattern A2 was obtained from a liver and heart swab from a bird (bird 7). Pattern A2 were distinguished from pattern A1 by one-band difference. Eight isolates from four birds in flock 2 belonged to PFGE patterns A1 $(n=3), B(n=3)$, and A3 $(n=2)$. In flock 3 , two isolates from 2 birds and four isolates from 3 birds showed identical patterns A2 and A4, respectively. The other isolate from a flock 3-bird had pattern C (Table 1).

Eighteen of the 26 isolates harbored putative virulence genes, ast $A$, iss, papC, iucD, tsh and $c v a / c v i$. These genes were detected in all the isolates belonging to PFGE patterns $\mathrm{A} 1, \mathrm{~A} 2$, and A3. All the above genes except for the papC gene were also detected in all the 4 isolates with PFGE pattern A4. Three isolates with PFGE pattern B carried the iss, irp2, and iucD genes, and the ast $A$, papC, tsh, vat, and $c v a /$ $c v i$ genes were not detected. In the PFGE pattern $C$ isolate, all virulence-associated genes examined except for the papC gene were found (Table 1).

\section{DISCUSSION}

E. coli was considered as the causative agent of the septicemia and mortality of birds in a commercial layer farm investigated. This is the first outbreak of colibacillosis in the present farm in which commercial layer chickens have been reared for more than 10 years [10]. The characteristic 

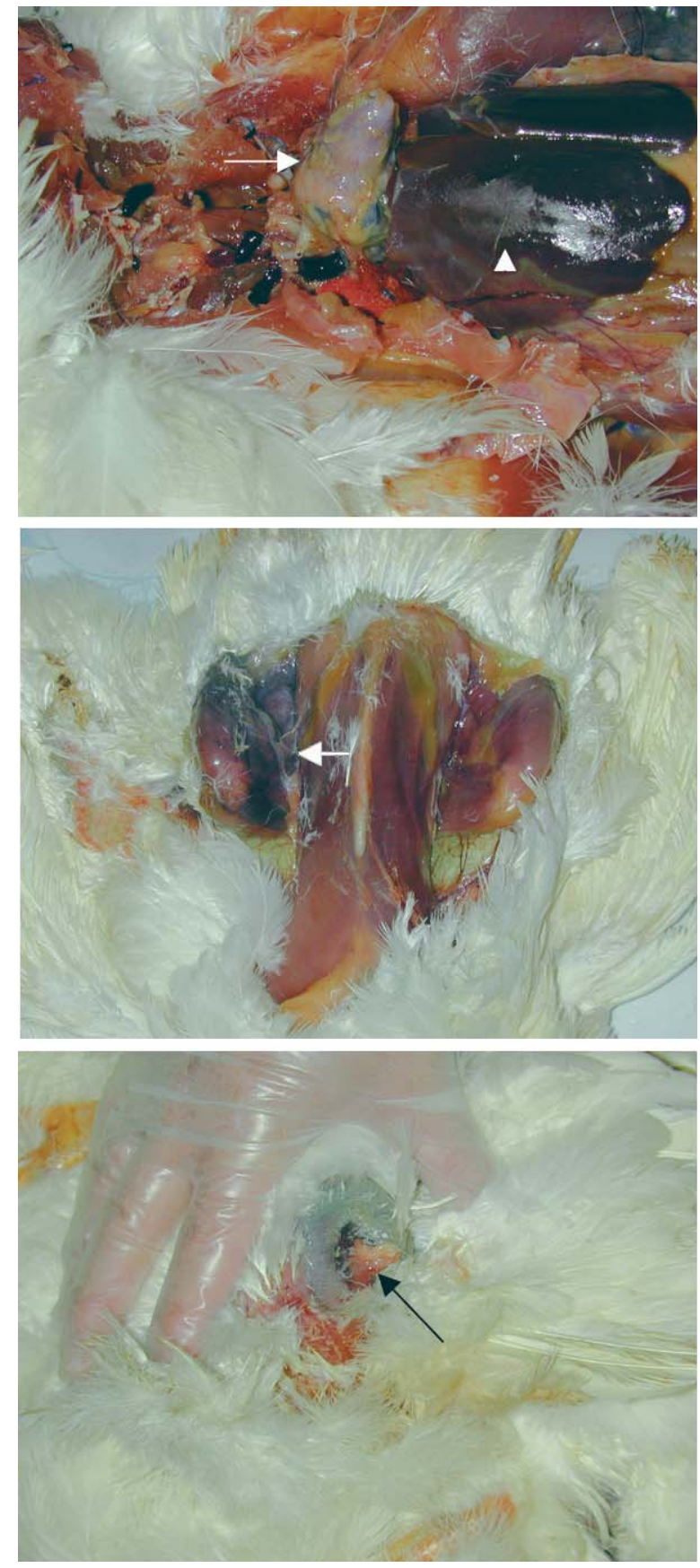

Fig. 2. Lesions in chickens with colibacillosis. (A) Pericarditis covered with a light-yellow exudates (arrow) and perihepatitis with fibrinous exudates (arrowhead). (B) Extensive reddishblack inguinal lesions (arrow). (C) Cloaca showing edema and hemorrhage (arrow).

lesions in this case were polyserosistis, including pericarditis, perihepatitis, and airsacculitis, inguinal discoloration, and injured cloaca. Our results demonstrated that genetically related strains caused the incidence of colibacillosis in three flocks. E. coli isolated from the lesions of the affected

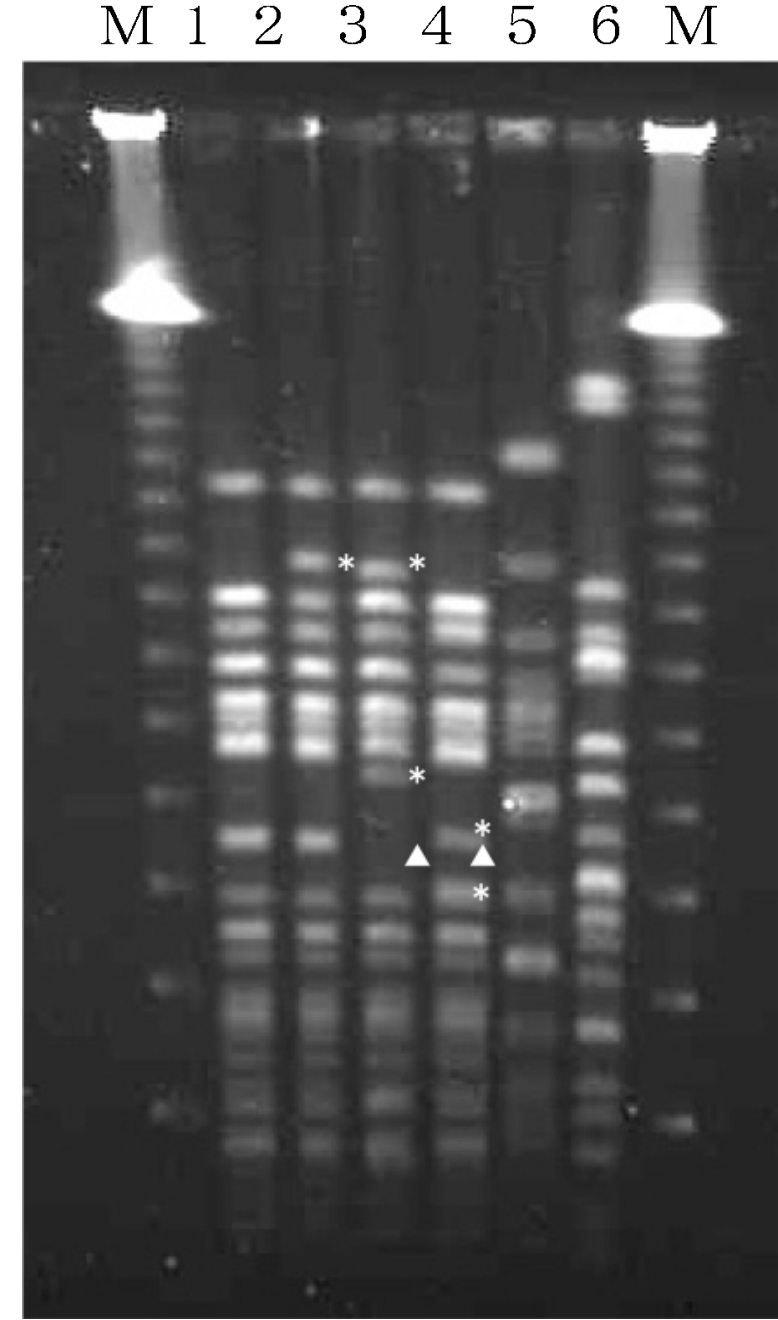

Fig. 3. Representative PFGE patterns of XbaI-digested chromosomal DNA of $E$. coli isolates obtained from the affected chickens. Lanes: 1, pattern $\mathrm{A} 1 ; 2$, pattern $\mathrm{A} 2 ; 3$, pattern $\mathrm{A} 3 ; 4$, pattern A4; 5, pattern B; 6, pattern C; M, lambda DNA ladder. Triangles indicate fragments present in pattern A1 and unfound in patterns $\mathrm{A} 3$ and $\mathrm{A} 4$; asterisks indicate fragments present in patterns $\mathrm{A} 2, \mathrm{~A} 3$, and $\mathrm{A} 4$ and unfound in pattern $\mathrm{A} 1$.

birds in all 3 flocks exhibited any of PFGE patterns A1 to A4, which are considered to be closely related according to the established criteria for subtyping of bacteria by PFGE [14]. Furthermore, the combination of virulence associated genes, astA, iss, papC, iucD, tsh, and cva/cvi gene was also identical among 18 isolates that showed PFGE pattern A1, $\mathrm{A} 2$, and A3. Three-band differences between pattern A4 and pattern A1 may be responsible for the presence or absence of the papC gene.

Additional strains with different PFGE patterns (B and C) exhibiting more than 7-band differences from the pattern $\mathrm{A}$ isolates were also obtained from the affected birds. The combinations of the virulence-associated genes shown in the pattern $\mathrm{B}$ and $\mathrm{C}$ isolates were also different from pattern 
A isolates.

Two putative virulence genes, iss and iucD, were detected in all the isolates obtained from the affected birds. The iss gene that is associated with serum resistance can confer the ability to reach to the extra intestinal region through the blood stream. Aerobactin encoded by the iucD gene is a bacterial-derived siderophore which sequestors iron from the host environment for use in replication within the host. Although these genes may play an important role in pathogenicity, differences in the prevalence of these genes in affected chickens with colibacillosis have been reported. The iss gene has been detected in $38.5 \%$ to $90 \%$ of isolates from affected chickens $[2,4,9,12,16]$. Similarly, the frequencies of aerobactin genes were ranged from $77.7 \%$ to $97.4 \%[4,7,9,12,16]$. The remaining genes investigated in the present study were also detected at various frequencies $[2,4,7,9,12,16]$. Different combinations of the putative virulence genes were also observed in the isolates investigated. The association between these potential virulence genes and the pathogenicity of the organism remain unsolved. The emergence of colibacillosis may be associated with other factors that have not yet been investigated. Host factors such as compromised skin or mucosal barrier, stress, immunosuppression, and environmental factors may also be involved $[1,3]$. Coccidial infection observed in flock 2 may be associated with higher mortality observed in this flock than those in the other flocks without coccidiosis.

The age of the chickens is likely to be one of the factors associated with the occurrence of present cases. Increases in the mortality were observed during 18 and 21 weeks of age, when the birds started to produce eggs. Cloacal lesions observed in our study are likely due to the results of laying. These wounds may allow the organism to invade the blood stream. Zanella et al. [17] reported colibacillosis in the layers at the beginning of laying. They also suggested that hens exposed the stress of lay may have been more susceptible to colibacillosis.

No remarkable decrease in egg production was observed in the present cases. Zanella et al. [17] and Vandekerchove et al. [15] also reported the APEC infection without significant impact on the egg production and quality. The mortality in this case progressed on the low level of approximately 0.02 to $0.08 \%$ per day although the highest mortality was recorded as $0.16 \%$ in flock 2 . However, severe colibacillosis infection with more than $6 \%$ total mortality in laying hens has been reported $[3,17]$.

In conclusion, the 3 cases of colibacillosis were caused by not only strains with the PFGE pattern A but also those with the PFGE patterns $\mathrm{B}$ and $\mathrm{C}$ that were considered to be genetically unrelated to the pattern A strains. Thus, host factors, such as initiation of egg may also be associated with the incidence of colibacillosis.

ACKNOWLEDGEMENT. The authors are grateful to Dr. Peter S. Holt (Egg Safty and Quality Research Unit, United States Department of Agriculture, U.S.A) for reviewing the manuscript.

\section{REFERENCES}

1. Barnes, H.J. and Gross, W.B. 1997. Colibacillosis. pp. 131141. In: Diseases of Poultry, 10th ed. (Calnek, B.W., Barnes, H.J., Beard, C.W., McDougald, L.R. and Saif, Y.M. eds.), Iowa State University Press.

2. Delicato, E.R., de Brito, B.G., Gaziri, L.C. and Vidotto, M.C. 2003. Virulence-associated genes in Escherichia coli isolates from poultry with colibacillosis. Vet. Microbiol. 94: 97-103.

3. Dhillon, A.S. and Jack, O.K. 1996. Two outbreaks of colibacillosis in commercial caged layers. Avian Dis. 40: 742-746.

4. Ewers, C., Janben, T., Kiebling, S., Philipp, H.C. and Wieler, L.H. 2004. Molecular epidemiology of avian pathogenic Escherichia coli (APEC) isolated from colisepticemia in poultry. Vet. Microbiol. 104: 91-101.

5. Ewers, C., Janben, T., Kiebling, S., Philipp, H.C. and Wieler, L.H. 2005. Rapid detection of virulence-associated genes in avian pathogenic Escherichia coli by multiplex polymerase chain reaction. Avian Dis. 49: 269-273.

6. Ginns, C.A., Browning, G.F., Benham, M.L. and Whithear, K.G. 1998. Development and application of aerosol challenge method for reproduction of avian colibacillosis. Avian Pathol. 27: 505-511.

7. Janben, T., Schwarz, C., Preikschat, P., Voss, M., Philipp, H.C. and Wieler, L.H. 2001. Virulence-associated genes in avian pathogenic Escherichia coli (APEC) isolated from internal organs of poultry having died from colibacillosis. Int. J. Med. Microbiol. 291: 371-378.

8. La Ragione, R.M. and Woodward, M.J. 2002. Virulence factors of Escherichia coli serotypes associated with avian colisepticaemia. Res. Vet. Sci. 73: 27-35.

9. McPeake, S.J.W., Smyth, J.A. and Ball, H.J. 2005. Characterisation of avian pathogenic Escherichia coli (APEC) associated with colisepticaemia compared to faecal isolates from healthy birds. Vet. Microbiol. 110: 245-253.

10. Murase, T., Senjyu, K., Maeda, T., Tanaka, M., Sakae, H., Matsumoto, Y., Kaneda, Y., Ito, T. and Otsuki, K. 2001. Monitoring of chicken houses and an attached egg-processing facility in a laying farm for Salmonella contamination between 1994 and 1998. J. Food Prot. 64: 1912-1916.

11. Murase, T., Nagato, M., Shirota, K., Katoh, H. and Otsuki, K. 2004. Pulsed-field gel electrophoresis-based subtyping of DNA degradation-sensitive Salmonella enterica subsp. enterica serovar Livingstone and serovar Cerro isolates obtained from a chicken layer farm. Vet. Microbiol. 99: 139-143.

12. Rodriguez-Siek, K.E., Giddings, C.W., Doetkott, C., Johnson, T.J., Fakhr, M.K. and Nolan, L.K. 2005. Comparison of Escherichia coli isolates implicated in human urinary tract infection and avian colibacillosis. Microbiology 151: 20972110 .

13. Stordeur, P., Marlier, D., Blanco, J., Oswald, E., Biet, F., DhoMoulin, M. and Mainil, J. 2002. Examination of Escherichia coli from poultry for selected adhesin genes important in disease caused by mammalian pathogenic E. coli. Vet. Microbiol. 84: $231-241$.

14. Tenover, F.C., Arbeit, R.D., Goering, R.V., Mickelsen, P.A., Murray, B.E., Persing, D.H. and Swaminathan, B. 1995. Interpreting chromosomal DNA restriction patterns produced by pulsed-field gel electrophoresis: Criteria for bacterial strain typing. J. Clin. Microbiol. 33: 2233-2239.

15. Vandekerchove, D., De Herdt, P., Laevens, H. and Pasmans, F. 
2004. Colibacillosis in caged layer hens: characteristics of the disease and the aetiological agent. Avian Pathol. 33: 117-125.

16. Vandekerchove, D., Vandemaele, F., Adriaensen, C., Zaleska, M., Hernalsteens, J.P., De Baets, L., Butaye, P., Van Immerseel, F., Wattiau, P., Laevens, H., Mast, J., Goddeeris, B. and Pasmans, F. 2005. Virulence-associated traits in avian Escherichia coli: Comparison between isolates from colibacillosis- affected and clinically healthy layer flocks. Vet. Microbiol. 108: 75-87.

17. Zanella, A., Alborali, G.L., Bardotti, M., Candotti, P., Guadagnini, P.F., Anna Martino, P. and Stonfer, M. 2000. Severe Escherichia coli $\mathrm{O} 111$ septicaemia and polyserositis in hens at the start of lay. Avian Pathol. 29: 311-317. 